\title{
The Management of Inflammatory Bowel Disease in Elderly: Current Evidence and Future Perspectives
}

\author{
Ian Arnott ${ }^{\mathrm{a}} \quad$ Gerhard Rogler $^{\mathrm{b}} \quad$ Jonas Halfvarson ${ }^{\mathrm{c}}$ \\ ${ }^{a}$ Gastrointestinal Unit, Western General Hospital, Edinburgh, UK; ${ }^{b}$ Department of Gastroenterology and \\ Hepatology, University Hospital Zurich, Zurich, Switzerland; ' ${ }^{C}$ Department of Gastroenterology, Faculty of Medicine \\ and Health, Örebro University, Örebro, Sweden
}

\section{Keywords}

Comorbidities - Crohn's disease · Elderly .

Management of the disease $\cdot$ Ulcerative colitis

\begin{abstract}
Data on the elderly population with inflammatory bowel disease (IBD) are scarce, as this population is normally excluded from clinical trials. With an ageing population and an overall increasing prevalence of IBD; the incidence of IBD in elderly is rising. Comorbidities, wide differential diagnosis and polypharmacy make the diagnosis and management of the disease in elderly more challenging compared to that in younger adults. The knowledge of specific requirements for the management and treatment of IBD in advanced age may help in the framing of the definition of the appropriate care of this patient group. This manuscript reviews the most recent knowledge in the epidemiology, diagnosis and management of IBD in this population.

(c) 2018 S. Karger AG, Basel
\end{abstract}

\section{Introduction}

Age at the onset of inflammatory bowel disease (IBD) ranges from early childhood to beyond the seventh decade of life. Irrespective of the age at the time of diagnosis, IBD is relatively common in elderly individuals due to the chronic nature of the disease [1].

There is often a delay in achieving a correct diagnosis in elderly IBD due to the number of IBD-like symptoms that overlap with the symptoms of other diseases [2]. Because it takes a long time to make a diagnosis in the elderly population, the probability that prompt optimised disease management strategies are implemented from the very early stage of the disease gets reduced. The increased rate of misdiagnosis with advanced age [3], the presence of comorbidities and prevalence of polypharmacy in elderly subjects also greatly contribute to worsening the treatment outcome.

The elderly population with IBD is poorly represented in clinical trials [4], as many trials exclude individuals aged $>65$ years. This results in a relatively poor evidence

\section{KARGER}

(C) 2018 S. Karger AG, Basel

E-Mail karger@karger.com

www.karger.com/iid
Dr. Ian Arnott

Gastrointestinal Unit, Western General Hospital

Crewe Road South

Edinburgh EH4 2XU (UK)

E-Mail Ian.Arnott@nhslothian.scot.nhs.uk 
base to guide appropriate therapeutic management decisions in this population. The risk of treatment-related adverse effects, as well as of surgical complications, may increase with advanced age, thus emphasizing the need for good quality clinical data on which to base decisions [5]. The present review summarises the disease characteristics, the clinical presentation, the methods of evaluating and monitoring IBD and the specific challenges faced by elderly patients in terms of selecting the most appropriate disease management strategy.

\section{Epidemiology}

Currently, there is no accepted universal definition of the term "elderly." Although "elderly" is often defined as those with chronological age 65 years or older in most developed countries, there is still some discrepancy in terms of the threshold value from a healthcare perspective, given that other markers of old age, such as the general health state or the presence of concomitant diseases, may influence the physical mark of old age.

Previously published reviews on IBD in the elderly have set a threshold value of 60 years of age $[3,4,6,7]$, whereas the age of 65 years has been fixed as a reference value for the definition of elderly in other reports $[1,8,9]$.

Irrespective of the definition, the incidence and prevalence of IBD in the elderly are on the rise as a consequence of the ageing population. The evidence that IBD has relatively little effect on lifespan further contributes to the increase in the number of individuals aged $>65$ years living with IBD [8]. This increasing trend is more evident in highincome than in low-income countries, but the process of urbanisation, improved diagnostic methods and disease awareness have contributed to an increased IBD prevalence and incidence in regions such as Asia and the Middle East [10]. Thus, it is expected that the increase in the incidence of IBD diagnosed in advanced age will continue to further increase in the next decades on a worldwide basis [1].

Despite some variability of data across epidemiological studies due to regional differences and methods of diagnosis, the incidence rates of ulcerative colitis (UC) in the elderly are higher than those for Crohn's disease (CD) and range from 1 to 20/100,000 for UC in Europe and in the United States [6] compared to 1 to $10 / 100,000$ for CD in Europe [1,6]. A recently published National cohort study in Sweden has reported that $23 \%$ of subjects with diagnosed IBD had a first diagnosis of IBD at age $\geq 60$ years and that in elderly patients, the IBD incident rate was 35/100,000 person/years (male: 37; female: 33 ) and was
10/100,000 for CD, 19/100,000 for UC, and 5/100,000 for IBD unclassified [11].

Irrespective of the age at diagnosis, epidemiological studies have estimated that about $25-35 \%$ of individuals with IBD are $>60$ years of age [6].

\section{Diagnosis}

There are 2 distinct groups of elderly patients with IBD: those who have had IBD for several decades and those who have received a diagnosis later on in life (elderly-onset IBD) [4]. Overall, it is estimated that up to $15 \%$ of patients have been diagnosed after the age of 60 years, while up to $20 \%$ of these patients have been diagnosed earlier and have transitioned into older age $[4,6]$. In the previously mentioned National cohort study in Sweden [11], more than 1 out of 5 incidents of CD (21\%) and UC (24\%) cases occurred in elderly individuals. Notably, new diagnoses of UC are generally more common in elderly males than in females, with reversed rates for newly diagnosed CD [8].

\section{Time to Diagnosis is Longer in the Elderly}

Compared to younger adults, the initial diagnosis of IBD in the elderly is generally more difficult and consequently of longer duration. On average, there is a delay in diagnosis of up to 6 years in the elderly compared to 2 years in younger adults [3]. This is partly due to misdiagnosis: an initial incorrect diagnosis of CD was reported in 51 and $39 \%$ of elderly and younger patients respectively [12]. Factors that may account for this difference include access to specialist healthcare and the prevalence of conditions mimicking IBD, giving a wider differential diagnosis [1]. Delay in diagnosis may have a negative impact on disease outcome in terms of overall complications and progression to a stricturing and/or a penetrating disease, with a consequent increase in need for surgery [13].

\section{Clinical Characteristics of IBD in Elderly}

It is acknowledged that the natural history of elderlyonset IBD is less aggressive as compared to younger patients [14-16]. Elderly patients with CD have more colonic involvement with lower frequency of strictures and fistulas as compared to younger individuals, while elderly UC patients experience more commonly left-sided or extensive colitis vs. proctitis. Furthermore, in UC patients, the disease location tends to remain stable, with only $16 \%$ of individuals showing proximal disease extension at follow-up visit [15]. 
Although the clinical presentation of the disease differs frequently between elderly and younger individuals, age-related differences in clinical presentation are more evident in CD patients than in UC patients. Compared to younger adults, $\mathrm{CD}$ diagnosed in advanced age presents more often with rectal bleeding and less often with diarrhoea, abdominal pain and weight loss [4]. Conversely, the severity of symptoms of UC (especially rectal bleeding and diarrhoea) is usually milder in elderly than that in younger individuals, and the presentation in the elderly may be atypical [7].

As demonstrated in the EPIMAD study, elderly-onset $\mathrm{CD}$ subjects report less abdominal pain, systemic symptoms and diarrhoea, while subjects with a diagnosis of UC in older age report less abdominal pain and rectal bleeding [17].

More evident differences between elderly and younger adults emerge during the endoscopic examination and (to a lesser extent) from histopathology. Generally, the presence of isolated colonic inflammation with less frequent penetrating or perianal disease is a more common finding in elderly-onset $\mathrm{CD}$ and small bowel and upper gastrointestinal disease is less common $[4,15]$.

Because of phenotype-related differences and the presence of comorbidities, the management of IBD in the elderly may be different as compared to that of younger patients [14].

\section{Differential Diagnosis}

Differential diagnosis is one of the most important challenges for disease management, especially in older subjects. Several other diseases (such as ischemic colitis, motility disorders, drug side effects etc.) present clinical characteristics that may in part overlap with those of IBD. This may cause the above-mentioned delay in establishing the correct diagnostic process, or an incorrect diagnosis, which ultimately may lead to inappropriate therapy. Table 1 lists the most relevant differential diagnoses of IBD in the elderly.

\section{Management of the Disease in the Elderly}

\section{Challenges in the Management of IBD \\ Comorbidities, Polypharmacy and Treatment \\ Compliance}

Comorbid health conditions such as heart disease, diabetes, cancer, psychiatric disorders and arthritis are commonly present in elderly patients with IBD [15]. This contributes to a higher risk of complications and mortal- ity after a severe attack of UC or CD in advanced age [18]. Furthermore, polypharmacy has the potential to increase the risk of drug interactions, and drugs used in the treatment of IBD may contribute to either triggering or worsening concomitant diseases as is the case of diabetes or psychiatric disorders with steroid-based therapy, heart failure with anti-tumor necrosis factor (anti-TNF) monoclonal antibodies and cancer with immunomodulators (including lymphoma with thiopurines). This may lead to poorer prognosis and an increased risk of IBD-related complications.

Poor Adherence to Therapies is Common in IBD and is More Evident in the Elderly

The concurrent administration of multiple drugs in a significant proportion of elderly IBD patients further contributes to reduce the adherence to the prescribed therapy, and hence to worsen the course not only of the IBD, but also of the other comorbidities. The use of simplified once-daily medication regimens and the avoidance of unnecessary multiple concomitant medications may be associated with improved adherence to therapy and clinical outcome [19].

\section{Treatment Goals and Therapeutic}

Approaches - Differences with the General Population

Evolution of Treatment Goals in IBD: Clinical

Remission and Mucosal Healing

Treatment goals in IBD have been reviewed in recent years. The primary goal has evolved from achieving clinical remission towards the induction and maintenance of both clinical and endoscopic remission (i.e., mucosal healing), that is, the so-called deep remission. The evidence-based consensus from the European Crohn's and Colitis Organisation highlighted the importance of the evaluation of endoscopic mucosal inflammation even in the case of maintenance of symptom control, as mucosal healing correlates with reduced hospitalisation and surgeries [20].

\section{Patient-Reported Outcomes}

Patient-reported outcomes (PROs) have shown to offer important advantages over other more complicated composite endpoints, such as the CD Activity Index. PROs involve patients in the evaluation and in the management of their disease, as well as in sharing the management strategy with their physician. However, the patient perspective does not necessarily correlate with that of the physician, as physicians often tend to report fewer and milder symptoms than patients [21]. This may underes- 
Table 1. Differential diagnosis of inflammatory bowel disease (IBD; modified from $[1,4,6]$ )

\begin{tabular}{|c|c|c|}
\hline Disease & Clinical characteristics & Distinguishing findings \\
\hline $\begin{array}{l}\text { Infectious } \\
\text { gastroenteritis/ } \\
\text { colitis }\end{array}$ & $\begin{array}{l}\text { Acute onset of diarrhoea } \\
\text { with possible blood, } \\
\text { fever, dysentery }\end{array}$ & $\begin{array}{l}\text { Recent use of antibiotics, positive stool samples for } \\
\text { pathogen agents (e.g., Clostridium difficile), } \\
\text { pseudomembranes on endoscopy with Clostridium difficile, } \\
\text { positive stool studies, rapid resolution with appropriate } \\
\text { antibiotic therapy }\end{array}$ \\
\hline Ischaemic colitis & $\begin{array}{l}\text { Acute onset of abdominal } \\
\text { pain followed by bloody } \\
\text { diarrhoea, association with food intake }\end{array}$ & $\begin{array}{l}\text { Segmental area of injury, rectal sparing, typical } \\
\text { sigmoid/left sided colitis, rectum sparing, abrupt } \\
\text { transition between normal and affected mucosa, } \\
\text { possible concomitant cardiovascular disease }\end{array}$ \\
\hline Radiation colitis & $\begin{array}{l}\text { Bloody diarrhoea, abdominal pain, } \\
\text { urgency, tenesmus, symptoms occur } \\
\text { weeks to years after abdominal/pelvic radiation }\end{array}$ & $\begin{array}{l}\text { History of abdominal or pelvic radiation, histological } \\
\text { fibrosis and capillary telangiectasia (i.e., different findings } \\
\text { from IBD) }\end{array}$ \\
\hline Microscopic colitis & $\begin{array}{l}\text { Non-bloody diarrhoea, predominant } \\
\text { in females }\end{array}$ & $\begin{array}{l}\text { No anatomical abnormalities visible at endoscopy, } \\
\text { histologically different from IBD }\end{array}$ \\
\hline Diversion colitis & $\begin{array}{l}\text { Occurs in surgically diverted bowel loop, } \\
\text { most asymptomatic but can haveabdominal } \\
\text { pain and bloody/mucous discharge }\end{array}$ & Histologically, prominent lymphoid hyperplasia \\
\hline $\begin{array}{l}\text { Solitary rectal } \\
\text { ulcer syndrome }\end{array}$ & $\begin{array}{l}\text { Bloody diarrhoea with straining, rectal } \\
\text { bleeding, straining, pelvic fullness }\end{array}$ & $\begin{array}{l}\text { History of constipation, histologically thickened } \\
\text { mucosal layer and crypt architectural distortion, smooth } \\
\text { muscle and collagen replace lamina propria (i.e., different } \\
\text { findings from IBD) }\end{array}$ \\
\hline
\end{tabular}

NSAID, non-steroidal anti-inflammatory drugs.

timate the severity of the problem or may overestimate treatment improvement, while at the same time minimising potential drug-induced adverse effects. Thus, the use of simple patient-generated items derived from more complex instruments may be a valid tool to be used in clinical trials for the development of new drugs and for patient-driven clinical care. Simple 2-item PROs (PRO-2) derived from the CD Activity Index, such as the resolution of abdominal pain (abdominal pain $\leq 1$ ) and the normalisation of bowel habit (mean daily stool frequency $\leq 1.5$ ), have been shown to be appropriate for use in clinical trials in CD patients [22]. Similarly, a PRO-2 derived from the Mayo score consisting of resolution of rectal bleeding (score $=0$ ) and normalisation of bowel habit (stool frequency $\leq 1$ ) proved to be an appropriate measure in UC patients [23].
Although PROs have become important tools in the management of IBD, they have several limitations. First, PROs need to be validated over a complex process and not all PROs are currently validated for entering routine use in clinical trials or in clinical practice. Furthermore, PROs are generally based on subjective evaluation of symptoms: to not limit assessment to subjective components only, clinicians may tend to combine patient's evaluation of symptoms with the objective assessment of inflammation and disease severity based on laboratory markers and endoscopy. Finally, the use of PRO-2 as a primary endpoint in clinical trials will make comparison with older historical trials difficult. As the development and validation of PROs is derived from randomised clinical trials, from which elderly patients are generally excluded, there is little or no information 
on the appropriateness and validity of use of PROs in advanced age. Furthermore, PROs reporting may vary according to age range, and other factors, such as concomitant diseases or mood disturbances, which may affect the patient perception of subjective symptoms in older individuals.

Faecal Calprotectin and C-Reactive Protein

In addition to clinical and endoscopic evaluations, the determination of biomarker levels, such as C-reactive protein (CRP) and faecal calprotectin (FC) is useful for measuring disease activity in a non-invasive way and driving therapeutic decisions.

FC has been shown to be a reliable marker for assessing IBD disease activity [24] and in predicting mucosal healing and risk of relapse in CD patients [25-27]. CRP was also found to be a predictor of surgery in subgroups of patients with either UC or CD [28]. There is evidence that FC is superior to CRP in the prediction of clinical response and mucosal healing in IBD patients $[29,30]$.

There are scarce data on the predictive role of biomarkers in older individuals. Circulating levels of biomarkers in the elderly may be affected by complicating factors, such as the effects of comorbidities on CRP concentration. Moreover, several differential diagnoses with increased prevalence in older individuals (e.g., Clostridium difficile infection or ischaemic colitis) may be misinterpreted as a flare as they induce FC. For these reasons, research limited to elderly population is needed to better elucidate the value of non-invasive biomarkers in predicting the course of the disease.

\section{Medical Therapy: Therapeutic Approaches}

Step-Up versus Top-Down Approach

Different approaches that have been established in younger patients may also be used in the management of elderly IBD patients. Generally, a step-up approach, in which a conventional therapy is added if first-line treatment is ineffective, has been preferred for many years. As an example, oral/topical mesalazine and/or topical corticosteroids are generally used as starting therapy for mild to moderate UC, whereas systemic corticosteroids and biologicals (with azathioprine given during remission) are more often used in moderate/severe forms. However, studies have shown that a top-down approach, in which a potent agent is started at the early stage of the disease, such as an aggressive treatment with anti-TNF alpha agents, may be associated with reduced hospitalisation and surgeries in CD patients, which compensate the lower cost of traditional therapies, and with reduced risk of immunogenicity and associated infusion reactions. Thus, the to-down approach may offer the potential advantage of achieving disease stabilisation and minimising complications leading to surgery, while at the same time reducing the risk of adverse effects of corticosteroid therapy [31]. The current guidelines do not suggest differences between elderly and younger patients in the management of IBD. Therefore, the choice of the most appropriate therapeutic approach in older patients should be driven by balancing potential benefits and risks on an individual basis. Indeed, the increased risk in the use of drugs such azathioprine (e.g., lymphoma) or anti-TNF alpha agents (infections) should be evaluated taking into consideration the fact that refraining from these drugs may induce an underuse and increased risk of surgery.

\section{Treat to Target (STRIDE Recommendations)}

In the view of the limitations posed by the classical step-wise treatment intensification with re-evaluation of response according to symptoms, that is, the risk of under-treatment and of delay of highly effective therapy, a treat-to-target algorithm has been recently developed based on an evidence-based expert consensus process [32, 33]. The implementation of such strategy requires the definition of reliable targets (e.g., clinical/PRO remission) and the intensification of repeated tests (e.g., colonoscopy) with respect to the standard schedule used in clinical practice.

This approach may offer several advantages. First, it improves and accelerates treatment decisions by minimising the delay between changes in therapy. Then, treatment is intensified or de-escalated as appropriate according to each individual requirement. Most importantly, by identifying patients with a poor prognosis or at risk of relapse, this approach contributes to improve patient outcomes. Ultimately, the use of a treat-to-target algorithm has the potential to change the progressive course of IBD.

The most recent evidence of the advantages of this approach comes from the results of the completed CALM trial [34], which has showed that adjusting biologic therapy using tight monitoring and a treat-to-target strategy to normalise FC and CRP led to higher endoscopy healing rates and deep remission rates than just treating clinical symptoms.

Again, the lack of trials specifically conducted in the elderly population and the awareness that the evidenceand consensus-based recommendations on potential treatment targets for IBD is based on the review of systematic literature that largely excludes older individuals, does not lead to the understanding whether and to which 
Table 2. Summary of drug-drug interaction for 5-aminosalicylic acid (5-ASA/mesalazine) derivatives, corticosteroids and immunomodulators

\begin{tabular}{|c|c|}
\hline Drug class & Interactions \\
\hline 5-ASA derivatives & $\begin{array}{l}\text { 5-ASA increases the anticoagulant activity of warfarin } \\
\text { 5-ASA increases the risk of leukopenia if used in combination with thiopurines } \\
\text { Mesalazine reduces serum concentration (and efficacy) of digoxin } \\
\text { Mesalazine increases serum concentration (and the risk of adverse effects) of hydralazine and second } \\
\text { generation of anti-tuberculosis drugs } \\
\text { 5-ASA concentration increases if used with methotrexate }\end{array}$ \\
\hline Corticosteroids & $\begin{array}{l}\text { The efficacy of corticosteroids is reduced (due to increased clearance) with use of anti-epileptics } \\
\text { Corticosteroids may increase the anticoagulant activity of warfarin } \\
\text { Corticosteroids may reduce the effects of antidiabetic agents } \\
\text { The use of calcium channel blockers may increase the serum concentration (and the risk of adverse } \\
\text { effects) of corticosteroids } \\
\text { Corticosteroids may increase the hypokalaemic effects of diuretics }\end{array}$ \\
\hline Immunomodulators & $\begin{array}{l}\text { Thiopurines reduce the anticoagulant activity of warfarin } \\
\text { Thiopurines increase the risk of myelotoxicity if used with allopurinol (due to its xanthine } \\
\text { oxidase-mediated action) } \\
\text { Thiopurines increases the risk of leukopenia if used in combination with 5-ASA, clotrimazole } \\
\text { and angiotensin-converting enzyme inhibitors } \\
\text { Methotrexate concentration increases if used with 5-ASA derivatives, NSAIDs, } \\
\text { penicillin's or tetracyclines } \\
\text { Methotrexate may increase levels of theophyllines } \\
\text { Methotrexate may alter the concentration of loop diuretics and vice-versa } \\
\text { Azathioprine increases the effect of coumarin derivatives }\end{array}$ \\
\hline
\end{tabular}

extent the use of a treat-to-target approach may help in the management of IBD in elderly. It should also be considered that the use of frequent colonoscopies for the assessment of endoscopic remission in elderly and comorbid patients might be inappropriate, and that the presence of comorbidities may also make physicians less willing to investigate fully. This may also contribute to a delay in diagnosis.

Hospital Admission and Mortality: Tailored

Treatment to Avoid Admission

IBD is associated with significant rates of patients undergoing surgery. The lifetime risk of surgery has been estimated to reach $70-80 \%$ for CD and $20-30 \%$ in UC, although rates for surgery vary between countries and regions [35]. Recent studies suggest that mortality rates in IBD patients seem higher than previously estimated, and there are emerging threats to mortality. In fact, the postoperative mortality accounts only for a small proportion of death in IBD patients, and other emerging new threats, such as Clostridium difficile infection, malignancy, cerebrovascular disease, thrombosis and adverse effects of medical treatment, may contribute to increased risk of deaths [36].
Elderly IBD patients have more frequent hospital admissions and may have substantially higher postoperative mortality and more complications than younger patients $[11,37]$. In particular, the risk of thrombotic complications of IBD during hospitalisation is increased in elderly IBD patients as a consequence of disease-related hypercoagulability, reduced mobility and dehydration [1].

\section{Specific Therapeutic Considerations}

Although the available drugs for the treatment of IBD in the elderly are the same as those used in younger patients and the effects of medical therapy are not related with age, the speed of response may be slower in advanced age, and there are several therapy-specific factors that may increase the risk of unfavourable outcome in elderly IBD patients [8]. Table 2 summarises the potential drugdrug interactions for 5-ASA derivatives, corticosteroids and immunomodulators, which should be taken as reference prior to considering the choice of therapy in elderly IBD patients, as they can affect the efficacy and safety of treatments for both IBD and comorbidities.

Therapies prescribed to elderly often differ from those used in younger subjects. A retrospective study conducted in the US has shown that $\geq 40$ and $35 \%$ of elderly pa- 
tients use IBD maintenance treatment with 5-ASA and corticosteroids, respectively, compared to a low utilisation of immunomodulator and biologic agents. On average, elderly patients with IBD used a mean number of 7 concomitant drugs [38].

Although the use of each drug class is associated with its own specific risks, advanced age and the presence of comorbidities are risk factors for infections in IBD patients, irrespective of the type of treatment. The increased risk of infections, which is specific for each immunosuppressant drug, appears to be the most relevant age-specific feature to be taken into consideration. The lack of clinical trials investigating the effects of immunomodulators for the management of IBD in the elderly does not allow a reliable quantification of this risk.

Although its risk-benefit ratio should be evaluated in randomised clinical trials, there is recent evidence that leukocyte apheresis, an extracorporeal therapy that produces anti-inflammatory effects by removing activates leukocytes or platelets from peripheral blood, may be a safe and effective therapeutic option for UC in the elderly. In particular, the rate of adverse effects related to infections following leukocyte apheresis is generally low and similar in younger and elderly UC patients [39]. The potential advantages of this therapy in terms of safety should be balanced against the length of time required for the procedure and hence the potential delay of intensified treatment next to leukocyte apheresis if it was not effective.

\section{5-Aminosalicylic Acid (5-ASA/Mesalazine)}

5-ASAs are first-line treatment for the induction and maintenance of remission in mild to moderate UC, while they have no effect in CD. Overall, the elderly tend more likely to receive 5-ASA than immunomodulators and corticosteroids [8]. The efficacy of 5-ASA compounds is generally comparable in both younger and older patients and 5-ASA is largely used in the elderly due to its acceptable safety profile. Although once-daily dosing and foam formulations of topical therapy might increase compliance to therapy, adherence rates to 5-ASA are suboptimal in elderly due to the lack of the necessary dexterity to administer enemas and/or oral forms, as well as due to the need to adjust the volume of enema formulations in case of the presence of faecal incontinence [9]. Important drug interactions of 5-ASA are reported with warfarin. The half-life of 5-ASA derivatives can be increased in the elderly due to a reduction in glomerular filtration and renal clearance. Due to this, the monitoring of renal function during 5-ASA therapy is required, especially in patients with pre-existing renal impairment, or in the case of concomitant use of other potentially

Management of IBD in the Elderly nephrotoxic drugs [38]. Other important interactions of mesalazine with drugs commonly used in the elderly include digoxin (reduced serum concentration and efficacy), hydralazine and the second generation of anti-tuberculosis drugs (increased serum concentration and risk of adverse effects) [9]. The availability of several 5-ASA formulations and the potential drug interaction profile highlight the importance of optimising the formulation and administration based on the individual patient requirements.

\section{Corticosteroids}

Corticosteroids are used for the treatment of IBD because of their effectiveness in the management of acute symptoms. However, the use of corticosteroids in the treatment of IBD in elderly people carries additional risks. The prolonged use of corticosteroids predisposes patients to cataracts and glaucoma, or precipitates/exacerbates preexisting conditions, such as diabetes, hypertension, osteoporosis or mental state alterations. The risk of fractures in the elderly is enhanced, as corticosteroid therapy is associated with malabsorption and malnutrition. Prolonged steroid therapy increases the risk of infections (especially fungal infections) and associated complications. The risk of gastrointestinal haemorrhage is also increased when corticosteroids are given in association with non-steroidal antiinflammatory drugs [9]. Moreover, ageing CD patients treated with steroids are at a significantly increased risk for developing hypokalaemia and mental status changes [40, 41]. Due to these reasons, it has been estimated that only $25-33 \%$ of elderly IBD patients are treated with corticosteroids [8], even though recent data from Sweden indicate these figures represent an underestimation of the cumulative exposure to steroids [11]. Although budesonide seems to be a preferable option as it interferes less with bone metabolism, repeated bone densitometry and vitamin $\mathrm{D} / \mathrm{cal}$ cium supplementation are still required for the prevention of bone loss. Corticosteroids given in combination with other immunosuppressive agents increase the risk of serious infections [42]. Corticosteroid clearance is decreased in the elderly, which exposes patients to increased risk of corticosteroids-induced adverse effects. Modified-release formulations of budesonide or the multi-matrix budesonide formulation are considered the first-line option for elderly population due to their improved safety profile, while retaining the anti-inflammatory properties of budesonide.

\section{Immunomodulators}

The response to immunomodulator therapy is the same in elderly patients and younger adults [7]. 6-mercaptopurine or azathioprine is used in approximately $6 \%$ 
of cases, with only $1 \%$ of patients receiving methotrexate [38]. This low use of immune-modifying agents is likely to be due to the risk of severe adverse effects and the requirements for blood test monitoring, especially in elderly patients. Known adverse events include leucopenia and transaminases increase, allergic reactions, mild (nausea and dyspepsia) or severe (acute pancreatitis) gastrointestinal adverse effects, increased risk of or non-melanoma skin cancer. Adverse effects associated with the use of methotrexate include nausea, fatigue, stomatitis, rash and, most importantly, worsening of hypertension and renal insufficiency, which are common comorbidities in elderly subjects. The risk of non-Hodgkin's lymphoma with thiopurines, especially when given in combination with anti-TNF therapy, is also increased in males aged $>60$ years $[1,4]$. Compared with the expected rate of non-Hodgkin's lymphoma in the general population, it has been estimated that thiopurine-treated subjects had a threefold increased risk [43].

Finally, as thiopurines have a large spectrum of druginteractions, their use in the elderly requires dose adjustments [8]. As an example, 6-mercaptopurine and azathioprine require dose reduction and monitoring of liver function when given in conjunction with allopurinol, as this is the case for methotrexate when used together with 5-ASA derivatives [3]. Azathioprine increases the effect of coumarin derivatives, requiring close monitoring of the prothrombin time in case of co-administration [9].

\section{Anti-TNF}

The role of anti-TNF therapy in inducing clinical and histological remission and in decreasing rates of hospitalisation and surgery in moderate to severely active IBD patients has been established [1]. However, it has been estimated that anti-TNF agents are used as part of maintenance therapy in less than $10 \%$ of older CD and only in $1-2 \%$ of older UC patients due to the risk of adverse effects or complications $[4,11]$. A recent observational retrospective study [44] has shown that elderly patients treated with anti-TNF have a significantly lower rate of short-term clinical response (68\% in the elderly vs. $89 \%$ in younger patients) and a higher risk of severe adverse events than the younger patients receiving the same treatment. There is evidence derived from the use of this drug class in rheumatic diseases suggesting that there is a trend towards an increased risk of infections in subjects aged $>65$ years [7]. This trend has been confirmed in a study conducted in Italy [45], in which IBD patients older than 65 years treated with TNF inhibitors had a higher rate of severe infections and mortality compared with younger patients or patients of the same age not receiving these agents. However, it should be taken into consideration that combination therapy or other treatments for comorbid conditions may contribute to this trend [7]. Other important adverse effects reported with the use of anti-TNF agents in elderly patients include exacerbation of congestive heart failure, dermatological reactions, infusion reactions and neurological sequelae $[1,4]$. In general, monotherapy should be preferred in patients requiring anti-TNF therapy.

Surgery

Taking into consideration that approximately $25 \%$ of IBD surgeries are performed in patients aged $>55$ years, specific considerations for the elderly IBD population should be made for surgical therapy.

The rate of elderly patients undergoing surgery is higher than that of younger adults for CD [11], whereas surgery rates for UC are less age-dependent [8]. Although surgical indications in older patients are the same as those for younger subjects [7], post-operative mortality and rates of complications are higher in the elderly than that in younger subjects [4].

Although toxic megacolon is a potentially fatal complication of colonic inflammation, it is not an absolute indication for immediate colectomy. Time for surgery in toxic megacolon remains controversial, with advocates for early surgery to avoid further complication and advocates for timely medical treatment to avoid surgery complication. Epidemiological data on toxic megacolon are very scarce, with large studies dating back to 1980. It is therefore difficult to extrapolate the epidemiology of this complication in the elderly population. According to Autenrieth et al. [46], the epidemiology of toxic megacolon has shifted towards infection causes, particularly due to an increase of Clostridium difficile-associated colitis and possible use/abuse of antibiotics. A recent survey conducted in the United States concluded that elderly patients with UC are at increased risk for infectious complications and postoperative venous thromboembolism, and that the length of hospital stay was longer in elderly than in subjects aged $<65$ years [47]. This evidence has been confirmed in a recent large-population cohort study [48] that included 21,218 IBD subjects (approximately $12 \%$ of elderly-onset patients), which showed that elderly-onset UC patients were more likely to undergo surgery and that elderly-onset CD patients had a higher rate of IBD-specific mortality compared to those with younger-onset disease. Although there is some evidence to suggest a decrease in UC-related mortality rates over the last decade, advanced age and co- 
morbidities are still significantly associated with 3-year mortality, thus suggesting that other age-related conditions (e.g., comorbid state and polytherapy) further increase the inherent risk [49].

The used surgical technique has little influence on post-operative outcome. In fact, restorative proctocolectomy with ileal pouch-anal anastomosis continues to be the surgical technique of choice in UC patients and the pouch failure rates observed in older patients are similar to those reported in younger subjects. However, the elderly are more likely to need urgent colectomy, which is associated with an increased risk of mortality, particularly in the presence of comorbidities. In fact, comorbid conditions play a major role in the increased post-operative risk in elderly IBD. A large database study [50] that examined the surgical outcome in more than 35,000 patients who underwent IBD-related operations showed that common comorbidities of elderly, such as congestive heart failure, thromboembolic disease and renal disease, were associated with a significant increase in mortality rate. The evidence of the increased risk of post-operative complications in elderly IBD patients suggest that preexisting comorbidities, nutritional status and general health condition should be carefully evaluated, possibly referring to a multidisciplinary care, prior to consider surgical options in elderly IBD patients.

These findings indicate that a more optimised disease management should be advocated in elderly IBD patients to reduce postoperative risks and risk of mortality in general. These increased risks need to be considered when deciding the most appropriate management strategy. At the same time, delaying surgery in elderly IBD patients in which surgical therapy is indicated increases the risk of poor outcome [6].

\section{Conclusions}

IBD is relatively common in elderly subjects, with up to $35 \%$ of patients with IBD aged $\geq 60$ years. However, clinical data on the characteristics and the outcome of the disease in advanced age are scarce.

Management of IBD in the elderly poses specific challenges. Diagnosis takes longer and misdiagnosis is also more common. Several diseases may mimic the clinical presentation of IBD and accurate differentiation is needed for appropriate management. Treatment of IBD in this special population is complicated by the presence of comorbidities and by the risk of drug interactions, which is exacerbated by polypharmacy. Cognitive decline and psy- chiatric diseases, which are relatively common in elderly, further contribute to decreased adherence to therapy.

Improving communication between the patient and the physician in decisions on the choice of the most suitable approach may allow for rapid implementation of the most appropriate disease management on an individual basis. Further studies specifically limited to the elderly population would help greatly to increase the knowledge of the characteristics of the disease in advancing age and hence to better define the diagnostic process and the therapeutic strategy.

\section{Acknowledgements}

The authors thank P. Marchi and H. Thorne from Tillotts Pharma AG and Luca Cantini for medical writing and administrative support.

\section{Disclosure Statement}

I.A. has received travel support and advisory board honorarium from Vifor Pharma, speaking fees from Takeda, Ferring and Tillotts. G.R. has consulted to Abbvie, Augurix, BMS, Boehringer, Calypso, Celgene, FALK, Ferring, Fisher, Genentech, Gilead, Janssen, MSD, Novartis, Pfizer, Phadia, Roche, UCB, Takeda, Tillotts, Vifor, Vital Solutions and Zeller; G.R. has received speaker's honoraria from Astra Zeneca, Abbvie, FALK, Janssen, MSD, Pfizer, Phadia, Takeda, Tillotts, UCB, Vifor and Zeller; G.R. has received educational grants and research grants from Abbvie, Ardeypharm, Augurix, Calypso, FALK, Flamentera, MSD, Novartis, Pfizer, Roche, Takeda, Tillotts, UCB and Zeller. J.H. has received consulting fees from Abbvie, Celgene, Ferring, Hospira, Janssen, Medivir, MSD, Pfizer, RenapharmaVifor, Sandoz, Shire, Takeda, and Tillotts Pharma, and lecture fees from Abbvie, Ferring, Janssen, MSD, RenapharmaVifor, Shire, Takeda and Tillotts Pharma. J.H. has received research grants from Janssen, MSD and Takeda.

\section{References}

1 Nimmons D, Limdi JK: Elderly patients and inflammatory bowel disease. World J Gastrointest Pharmacol Ther 2016;7:51-65.

2 Hussain SW, Pardi DS: Inflammatory bowel disease in the elderly. Drugs Aging 2010;27: 617-624.

3 Katz S, Pardi DS: Inflammatory bowel disease of the elderly: frequently asked questions (FAQs). Am J Gastroenterol 2011;106:18891897.

4 Taleban S, Colombel JF, Mohler MJ, Fain MJ: Inflammatory bowel disease and the elderly: a review. J Crohns Colitis 2015;9:507-515.

$5 \mathrm{Ha} \mathrm{CY}$, Katz S: Clinical outcomes and management of inflammatory bowel disease in the older patient. Curr Gastroenterol Rep 2013;15:310. 
6 Sturm A, Maaser C, Mendall M, Karagiannis D, Karatzas P, Ipenburg N, Sebastian S, Rizzello F, Limdi J, Katsanos K, Schmidt C, Jeuring S, Colombo F, Gionchetti P: European Crohn's and colitis organisation topical review on IBD in the elderly. J Crohns Colitis 2017;11:263-273

7 del Val JH: Old-age inflammatory bowel disease onset: a different problem? World J Gastroenterol 2011;17:2734-2739.

8 Stepaniuk P, Bernstein CN, Targownik LE, Singh H: Characterization of inflammatory bowel disease in elderly patients: A review of epidemiology, current practices and outcomes of current management strategies. Can J Gastroenterol Hepatol 2015;29:327-333.

9 Prelipcean CC, Mihai C, Gogalniceanu P, Mihai $\mathrm{B}$ : What is the impact of age on adult patients with inflammatory bowel disease? Clujul Med 2013;86:3-9.

10 Molodecky NA, Soon IS, Rabi DM, Ghali WA, Ferris M, Chernoff G, Benchimol EI, Panaccione R, Ghosh S, Barkema HW, Kaplan GG: Increasing incidence and prevalence of the inflammatory bowel diseases with time, based on systematic review. Gastroenterology 2012;142:46-54.

11 Everhov ÅH, Halfvarson J, Myrelid P, Sachs MC, Nordenvall C, Söderling J, Ekbom A, Neovius M, Ludvigsson JF, Askling J, Olén O: Incidence and Treatment of Patients Diagnosed With Inflammatory Bowel Diseases at 60 Years or Older in Sweden. Gastroenterology 2018;154:518-528.e15.

12 Wagtmans MJ, Verspaget HW, Lamers CB, van Hogezand RA: Crohn's disease in the elderly: a comparison with young adults. J Clin Gastroenterol 1998;27:129-133.

13 Nguyen VQ, Jiang D, Hoffman SN, Guntaka S, Mays JL, Wang A, Gomes J, Sorrentino D: Impact of diagnostic delay and associated factors on clinical outcomes in a U.S. Inflammatory bowel disease cohort. Inflamm Bowel Dis 2017;23:1825-1831.

14 Lobatón T, Ferrante M, Rutgeerts P, Ballet V, Van Assche G, Vermeire S: Efficacy and safety of anti-TNF therapy in elderly patients with inflammatory bowel disease. Aliment Pharmacol Ther 2015;42:441-451.

15 Charpentier C, Salleron J, Savoye G, Fumery M, Merle V, Laberenne JE, Vasseur F, Dupas JL, Cortot A, Dauchet L, Peyrin-Biroulet L, Lerebours E, Colombel JF, Gower-Rousseau C: Natural history of elderly-onset inflammatory bowel disease: a population-based cohort study. Gut 2014;63:423-432.

$16 \mathrm{Ha} \mathrm{CY}$, Katz S: Clinical implications of ageing for the management of IBD. Nat Rev Gastroenterol Hepatol 2014;11:128-138.

17 Ananthakrishnan AN, Shi HY, Tang W, Law CC, Sung JJ, Chan FK, Ng SC: Systematic review and meta-analysis: phenotype and clinical outcomes of older-onset inflammatory bowel disease. J Crohns Colitis 2016;10:1224-1236.

18 Katz S, Feldstein R: Inflammatory bowel disease of the elderly: a wake-up call. Gastroenterol Hepatol (N Y) 2008;4:337-347.
19 Lakatos PL: Prevalence, predictors, and clinical consequences of medical adherence in IBD: how to improve it? World J Gastroenterol 2009;15:4234-4239.

20 Gomollón F, Dignass A, Annese V, Tilg H, Van Assche G, Lindsay JO, Peyrin-Biroulet L, Cullen GJ, Daperno M, Kucharzik T, Rieder F, Almer S, Armuzzi A, Harbord M, Langhorst J, Sans M, Chowers Y, Fiorino G, Juillerat P, Mantzaris GJ, Rizzello F, Vavricka S, Gionchetti P; ECCO: 3rd European evidencebased consensus on the diagnosis and management of Crohn's disease 2016: part 1: diagnosis and medical management. J Crohns Colitis 2017;11:3-25.

21 Schreiber S, Panés J, Louis E, Holley D, Buch M, Paridaens K: National differences in ulcerative colitis experience and management among patients from five European countries and Canada: an online survey. J Crohns Colitis 2013;7:497-509.

22 Khanna R, Zou G, D'Haens G, Feagan BG, Sandborn WJ, Vandervoort MK, Rolleri RL, Bortey E, Paterson C, Forbes WP, Levesque BG: A retrospective analysis: the development of patient reported outcome measures for the assessment of Crohn's disease activity. Aliment Pharmacol Ther 2015;41:77-86.

23 Jairath V, Khanna R, Zou GY, Stitt L, Mosli M, Vandervoort MK, D'Haens G, Sandborn WJ, Feagan BG, Levesque BG: Development of interim patient-reported outcome measures for the assessment of ulcerative colitis disease activity in clinical trials. Aliment Pharmacol Ther 2015;42:1200-1210.

24 Lin JF, Chen JM, Zuo JH, Yu A, Xiao ZJ, Deng FH, Nie B, Jiang B: Meta-analysis: fecal calprotectin for assessment of inflammatory bowel disease activity. Inflamm Bowel Dis 2014;20:1407-1415.

25 Røseth AG, Aadland E, Grzyb K: Normalization of faecal calprotectin: a predictor of mucosal healing in patients with inflammatory bowel disease. Scand J Gastroenterol 2004;39: 1017-1020.

26 Louis E, Mary JY, Vernier-Massouille G, Grimaud JC, Bouhnik Y, Laharie D, Dupas JL, Pillant H, Picon L, Veyrac M, Flamant M, Savoye G, Jian R, Devos M, Porcher R, Paintaud G, PiverE, ColombelJF, Lemann M; Groupe D'etudes Thérapeutiques Des Affections Inflammatoires Digestives: Maintenance of remission among patients with Crohn's disease on antimetabolite therapy after infliximab therapy is stopped. Gastroenterology 2012;142:63-70.

27 Zhulina Y, Cao Y, Amcoff K, Carlson M, Tysk C, Halfvarson J: The prognostic significance of faecal calprotectin in patients with inactive inflammatory bowel disease. Aliment Pharmacol Ther 2016;44:495-504.

28 Henriksen M, Jahnsen J, Lygren I, Stray N, Sauar J, Vatn MH, Moum B; IBSEN Study Group: C-reactive protein: a predictive factor and marker of inflammation in inflammatory bowel disease. Results from a prospective population-based study. Gut 2008;57:15181523.
29 Schoepfer AM, Beglinger C, Straumann A, Trummler M, Vavricka SR, Bruegger LE, Seibold F: Fecal calprotectin correlates more closely with the Simple Endoscopic Score for Crohn's disease (SES-CD) than CRP, blood leukocytes, and the CDAI. Am J Gastroenterol 2010;105:162-169.

30 Schoepfer AM, Beglinger C, Straumann A, Safroneeva E, Romero Y, Armstrong D, Schmidt C, Trummler M, Pittet V, Vavricka SR: Fecal calprotectin more accurately reflects endoscopic activity of ulcerative colitis than the Lichtiger Index, C-reactive protein, platelets, hemoglobin, and blood leukocytes. Inflamm Bowel Dis 2013;19:332-341.

31 Hanauer SB: Clinical perspectives in Crohn's disease. Turning traditional treatment strategies on their heads: current evidence for "step-up" versus “top-down." Rev Gastroenterol Disord 2007;7(suppl 2):S17-S22.

32 Bouguen G, Levesque BG, Feagan BG, Kavanaugh A, Peyrin-Biroulet L, Colombel JF, Hanauer SB, Sandborn WJ: Treat to target: a proposed new paradigm for the management of Crohn's disease. Clin Gastroenterol Hepatol 2015;13:1042-1050.

33 Peyrin-Biroulet L, Sandborn W, Sands BE, Reinisch W, Bemelman W, Bryant RV, D’Haens G, Dotan I, Dubinsky M, Feagan B, Fiorino G, Gearry R, Krishnareddy S, Lakatos PL, Loftus EV Jr, Marteau P, Munkholm P, Murdoch TB, Ordás I, Panaccione R, Riddell RH, Ruel J, Rubin DT, Samaan M, Siegel CA, Silverberg MS, Stoker J, Schreiber S, Travis S, Van Assche G, Danese S, Panes J, Bouguen G, O'Donnell S, Pariente B, Winer S, Hanauer S, Colombel JF: Selecting therapeutic targets in inflammatory bowel disease (STRIDE): determining therapeutic goals for treat-to-target. Am J Gastroenterol 2015;110:1324-1338.

34 Colombel JF, Panaccione R, Bossuyt P, Lukas M, Baert FJ, Vanasek T, Danalioglu A, Novacek G, Armuzzi A, Hebuterne X, Travis SP, Danese S, Reinisch W, Sandborn WJ, Rutgeerts P, Hommes D, Schreiber S, Neimark E, Huang B, Zhou O, Patersson JH, Wallace K, Robinson AM, Thakkar RB, D'Haens G: Superior endoscopic and deep remission outcomes in adults with moderate to severe Crohn's disease managed with treat to target approach versus clinical symptoms: data from Calm. Gastroenterol 2017;152(suppl 1):S155.

35 Carter MJ, Lobo AJ, Travis SP; IBD Section, British Society of Gastroenterology: Guidelines for the management of inflammatory bowel disease in adults. Gut 2004;53(suppl 5):v1-v16.

36 Kassam Z, Belga S, Roifman I, Hirota S, Jijon H, Kaplan GG, Ghosh S, Beck PL: Inflammatory bowel disease cause-specific mortality: a primer for clinicians. Inflamm Bowel Dis 2014;20:2483-2492.

37 Ananthakrishnan AN, McGinley EL, Binion DG: Inflammatory bowel disease in the elderly is associated with worse outcomes: a national study of hospitalizations. Inflamm Bowel Dis 2009;15:182-189. 
38 Juneja M, Baidoo L, Schwartz MB, Barrie A 3rd, Regueiro M, Dunn M, Binion DG: Geriatric inflammatory bowel disease: phenotypic presentation, treatment patterns, nutritional status, outcomes, and comorbidity. Dig Dis Sci 2012;57:2408-2415.

39 Komoto S, Matsuoka K, Kobayashi T, Yokoyama Y, Suzuki Y, Hibi T, Miura S, Hokari $\mathrm{R}$ : Safety and efficacy of leukocytapheresis in elderly patients with ulcerative colitis: the impact in steroid-free elderly patients. J Gastroenterol Hepatol 2018, DOI: 10.1111/jgh.14116.

40 Dignass A, Van Assche G, Lindsay JO, Lémann M, Söderholm J, Colombel JF, Danese S, D’Hoore A, Gassull M, Gomollón F, Hommes DW, Michetti P, O'Morain C, Oresland T, Windsor A, Stange EF, Travis SP; European Crohn's and Colitis Organisation (ECCO): The second European evidence-based consensus on the diagnosis and management of Crohn's disease: current management. J Crohns Colitis 2010;4:28-62.

41 Akerkar GA, Peppercorn MA, Hamel MB, Parker RA: Corticosteroid-associated complications in elderly Crohn's disease patients. Am J Gastroenterol 1997;92:461-464.
42 Lichtenstein GR, Feagan BG, Cohen RD, Salzberg BA, Diamond RH, Price S, Langholff W, Londhe A, Sandborn WJ: Serious infection and mortality in patients with Crohn's disease: more than 5 years of follow-up in the TREATTM registry. Am J Gastroenterol 2012; 107:1409-1422.

43 Siegel CA, Marden SM, Persing SM, Larson RJ, Sands BE: Risk of lymphoma associated with combination anti-tumor necrosis factor and immunomodulator therapy for the treatment of Crohn's disease: a meta-analysis. Clin Gastroenterol Hepatol 2009;7:874881.

44 Lobatón T, Ferrante M, Rutgeerts P, Ballet V, Van Assche G, Vermeire S: Efficacy and safety of anti-TNF therapy in elderly patients with inflammatory bowel disease. Aliment Pharmacol Ther 2015;42:441-451.

45 Cottone M, Kohn A, Daperno M, Armuzzi A, Guidi L, D’Inca R, Bossa F, Angelucci E, Biancone L, Gionchetti P, Ardizzone S, Papi C, Fries W, Danese S, Riegler G, Cappello M, Castiglione F, Annese V, Orlando A: Advanced age is an independent risk factor for severe infections and mortality in patients given anti-tumor necrosis factor therapy for inflammatory bowel disease. Clin Gastroenterol Hepatol 2011;9:30-35.
46 Autenrieth DM, Baumgart DC: Toxic megacolon. Inflamm Bowel Dis 2012;18:584-591.

47 Bollegala N, Jackson TD, Nguyen GC: Increased postoperative mortality and complications among elderly patients with inflammatory bowel diseases: an analysis of the national surgical quality improvement program cohort. Clin Gastroenterol Hepatol 2016;14: 1274-1281.

48 Nguyen GC, Bernstein CN, Benchimol EI: Risk of Surgery and Mortality in Elderly-onset Inflammatory Bowel Disease: A Population-based Cohort Study. Inflamm Bowel Dis 2017;23:218-223.

49 Ventham NT, Kennedy NA, Duffy A, Clark DN, Crowe AM, Knight AD, Nicholls RJ, Satsangi J: Comparison of mortality following hospitalisation for ulcerative colitis in Scotland between 1998-2000 and 2007-2009. Aliment Pharmacol Ther 2014;39:1387-1397.

50 Kaplan GG, Hubbard J, Panaccione R, Shaheen AA, Quan H, Nguyen GC, Dixon E, Ghosh S, Myers RP: Risk of comorbidities on postoperative outcomes in patients with inflammatory bowel disease. Arch Surg 2011; 146:959-964. 